\title{
Intraoperative cholangiography during elective laparoscopic cholecystectomy. Selective or routine use? ${ }^{1}$
}

\author{
Alex Augusto Silva', Carlos Augusto Canteras Raposo Camara"I, Aiodair Martins Júnior ${ }^{\text {I }}$, Celso Júnior Oliveira Teles ${ }^{\text {II }}$, Júverson \\ Alves Terra Júnior ${ }^{\text {III }, ~ E d u a r d o ~ C r e m a ~}{ }^{\text {IV }}$ \\ ${ }^{\mathrm{I}} \mathrm{PhD}$, Associate Professor, Department of Surgery, Federal University of Triangulo Mineiro (UFTM), Uberaba-MG, Brazil. Helped with technical \\ procedures, critical revision. \\ II Graduate student, School of Medicine, UFTM, Uberaba-MG, Brazil. Scientific content of the study, English language, manuscript writing, critical \\ revision. \\ IIIMaster, Assistant Professor, Department of Surgery, UFTM, Uberaba-MG, Brazil. Intellectual and scientific content of the study, technical procedures, \\ critical revision. \\ ${ }^{\text {IV }} \mathrm{PhD}$, Full Professor, Department of Surgery, UFTM, Uberaba-MG, Brazil. Scientific content of the study, technical procedures, critical revision.
}

\section{ABSTRACT}

PURPOSE: To investigate clinical, laboratory and ultrasonographic parameters in patients with and without preoperative criteria for intraoperative cholangiography (IOC) during laparoscopic cholecystectomy in order to define predictive factors of choledocolithiasis.

METHODS: As a criterion for inclusion in the study the patients should present chronic calculous cholecystitis in the presence or absence of any recent clinical, laboratory of ultrasonographic finding suggesting choledocolithiasis, who were therefore submitted to cholangiography during surgery.

RESULTS: A total of 243 laparoscopic cholecystectomies with IOC were performed on patients with chronic calculous cholecystitis with or without a preoperative formal indication for contrast examination. Choledocolithiasis was detected in 33 (13.58\%) of the 243 patients studied. The incidence of previously unsuspected choledocolithiasis was only one case (1.0\%) among 100 patients without an indication for this exam. However, $32(22.37 \%)$ cases of choledocolithiasis were observed among the 143 patients with a preoperative indication for IOC.

CONCLUSION: The use of selective cholangiography is safe for the diagnosis of choledocolithiasis. Only $22.37 \%$ of the cholangiography results were positive in cases of suspected choledocolithiasis.

Key words: Cholecystectomy, Laparoscopic. Cholangiography. Choledocholithiasis. 


\section{Introduction}

Intraoperative cholangiography (IOC), described by Mirizzi in 1932, represented a significant advance in the diagnosis of choledocolithiasis during cholecystectomy ${ }^{1}$. The natural history of asymptomatic choledocolithiasis has been investigated in different populations and its therapeutic management continues to be controversial ${ }^{2}$.

IOC is traditionally advocated as a procedure to be adopted in all laparoscopic cholecystectomies since it permits to define the anatomy of the biliary tract and to detect common bile duct stones ${ }^{3,4}$. However, in the laparoscopic era, technological advances in radiologic-endoscopic workup have markedly increased the costs of investigation of patients with suspected choledocolithiasis. The routine use of IOC has raised the question of which cases require the exploration of bile tract anatomy during surgery and whether there are methods to predict preoperatively unsuspected choledocolithiasis ${ }^{3,5}$. Therefore, the most appropriate management of preoperatively unsuspected choledocolithiasis, i.e., the routine or selective use of IOC, still remains undefined. In this respect, well-defined criteria for the inclusion of patients with possible choledocolithiasis who should be submitted to cholangiography exist in the literature, but there is no safe approach to exclude asymptomatic patients without an indication for contrast examination ${ }^{6-9}$.

The objective of the present study was to investigate clinical, laboratory and ultrasonographic parameters in patients with and without preoperative criteria for IOC in order to define predictive factors of choledocolithiasis.

\section{Methods}

The study was approved by the Ethics Committee of Federal University of Triangulo Mineiro (UFTM) and all patients signed the free informed consent form before inclusion in the study.

In the present study, patients undergoing laparoscopic cholecystectomy with IOC were analyzed prospectively. As a criterion for inclusion in the study the patients should present chronic calculous cholecystitis in the presence or absence of any recent clinical, laboratory of ultrasonographic finding suggesting choledocolithiasis, who were therefore submitted to cholangiography during surgery ${ }^{10}$.

A total of 243 consecutive laparoscopic cholecystectomies with IOC performed between May 2008 and December 2009 on patients with chronic calculous cholecystitis with and a without a preoperative formal indication for contrast examination of the bile tract were analyzed. The following criteria were used in the present study for the preoperative indication of IOC: clinical findings such as a present or past history of jaundice, acute cholecystitis or acute pancreatitis in the last six months, laboratory parameters including elevated bilirubin and bile canalicular enzymes (alkaline phosphatase and gamma-glutamyltransferase), and imaging parameters (recent ultrasound showing dilatation of the bile duct and/or choledocolithiasis) ${ }^{6-11}$. Intraoperative IOC was indicated in the case of difficulty in the identification of the main bile duct.

A total of 243 patients whose clinical, laboratory and imaging parameters obtained within a maximum period of ten days before cholecystectomy indicated the presence or absence of preoperative alterations were included, corresponding to patients with suspected and unsuspected choledocolithiasis, respectively.

In all cases, cholangiography was preceded by the administration of a muscle relaxing agent (eosin/glucagon) and consisted of the slow injection of $30 \%$ iodinated contrast agent with a transparent catheter into the bile duct through the cystic duct, thus preventing spasm of the sphincter of Oddi. The technique described by Mirizzi ${ }^{1}$ was used and three radiographs were obtained: the first after the injection of 3-5 ml contrast agent into the biliary tract, the second after $3 \mathrm{~min}$ of an additional 3 $\mathrm{ml}$, and the third after the injection of a total of $15 \mathrm{ml}$ contrast agent. The first two radiographs permit the visualization of calculi, stenosis and passage of the contrast agent to the duodenum and demonstrated the absence of obstruction of the hepatic bile duct. The third radiograph permits the visualization of the intrahepatic biliary tree.

The cholangiographs were examined by the surgical team, by a radiologist and by the authors of this study. The reports were compared and correlated with the previous clinical and laboratory findings of the patients.

\section{Results}

A total of 243 laparoscopic cholecystectomies with IOC were performed on patients with chronic calculous cholecystitis with or without a preoperative formal indication for contrast examination. The mean duration of contrast examination was 17 min. Fifty-three $(21.81 \%)$ of the patients studied were males and $190(78.18 \%)$ were females. The mean age was 56.7 years for men and 43.2 years for women. There were $90.1 \%$ whites, $9.5 \%$ mulattoes, and $0.4 \%$ blacks.

Choledocolithiasis was detected in $33(13.58 \%)$ of the 243 patients studied. One-hundred patients had no preoperative 
indication for IOC and 143 had a preoperative indication. The incidence of preoperatively unsuspected choledocolithiasis was only one case among the 100 patients without an indication for the exam (Figure 1), corresponding to a positivity rate of cholangiography of $1.0 \%$ among patients with normal preoperative clinical, laboratory and imaging findings.

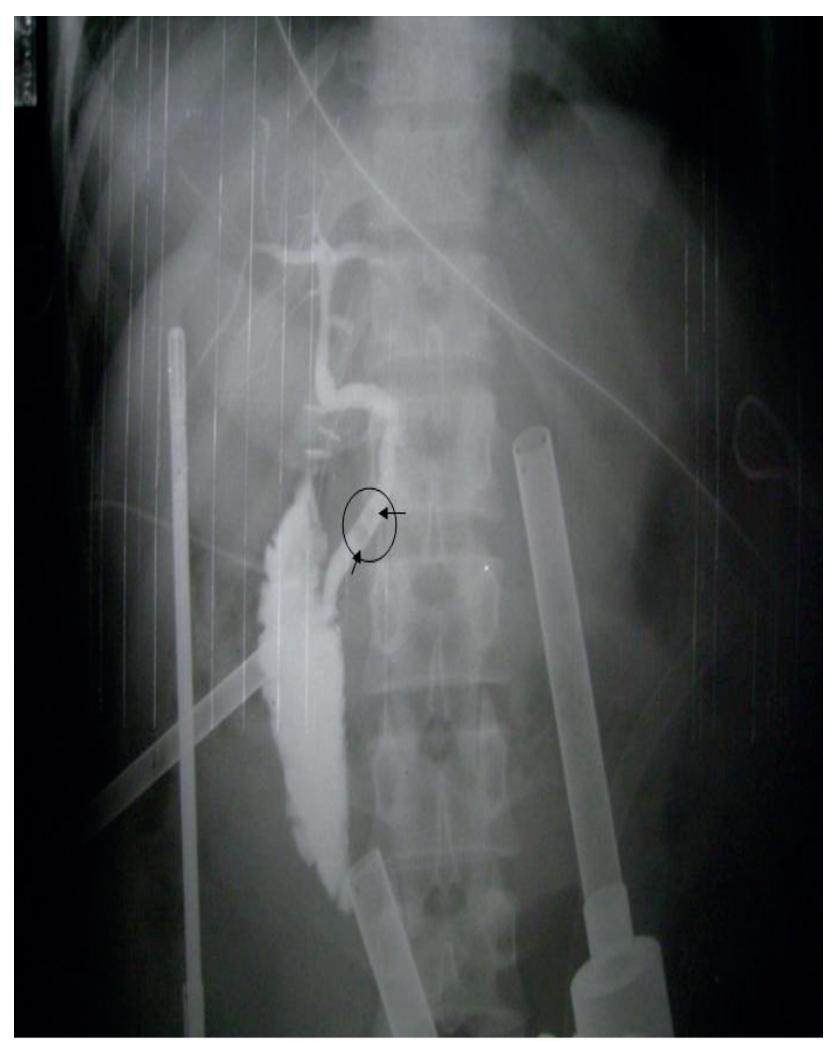

FIGURE 1 - Cholangiography using $15 \mathrm{ml}$ contrast agent. Observe the hepatic bile duct measuring $0.7 \mathrm{~cm}$ in width. It is noted two stones (arrow).

In contrast, there were 32 cases of choledocolithiasis among the 143 patients with a preoperative indication for IOC, corresponding to a positivity rate of the exam of $22.37 \%$. Thus, $77.63 \%$ of the cases of suspected choledocolithiasis were not confirmed by radiologic exploration of the biliary tract during surgery.

All cases of choledocolithiasis were treated by laparoscopy.

\section{Discussion}

After the advent of laparoscopic biliary surgery, the idea of a minimally invasive approach characterized by minimal access to the peritoneal cavity and technical agility during the procedure has emerged in an attempt to permit rapid postoperative recovery of the patient ${ }^{12-14}$. However, cholangiography is an invasive diagnostic method that may result in prolonged and unnecessary exploration of the main bile duct and acute pancreatitis, increasing the time of the surgical procedure under anesthesia and intraoperative morbidity and delaying discharge from the hospital ${ }^{14}$.

The combination of clinical, laboratory and ultrasonographic parameters for the preoperative suspicion of choledocolithiasis is a low-cost strategy and is available at medical centers with few resources. Although this combination has increased the probability of identifying choledocolithiasis, few models so far resemble the results of cholangiography. In poorly symptomatic patients, reassessment of clinical and laboratory parameters may contribute to the preoperative diagnosis of choledocolithiasis, guiding complementary investigations by radiologic methods ${ }^{2,8,15}$.

In the present study, the overall prevalence of choledocolithiasis was $13.58 \%$ and there was one case without a preoperative indication for contrast examination, in agreement with data in the literature. In a meta-analysis of the English literature involving an expressive series, Metcalfe et al. ${ }^{3}$ analyzed 4209 intraoperative cholangiographs of patients without a preoperative suspicion of choledocolithiasis. Cholangiography was positive in $170(4 \%)$ cases, a rate higher than that observed in the present study. The false-positive rate in that study was $0.8 \%$ (34 cases), a rate lower than that reported in the literature $(1.6 \%)$, which was explained by the authors by the improvement in the technical quality of cholangiography ${ }^{3}$

In the same study, Metcalfe et al. ${ }^{3}$ also analyzed 5179 preoperatively unsuspected laparoscopic cholecystectomies performed between 1995 and 2001 without IOC. Thirty-two $(0.6 \%)$ patients developed complications due to residual stones after follow-up, a rate approximately twice the value reported in other studies. The authors found no difference in the incidence of major or minor injuries between routine and selective IOC. There was also no association between anatomic anomalies and iatrogenic injuries to the bile duct, although iatrogenic injuries are more readily recognized in routine IOC.

No case of damage to the main bile duct was observed in the present study.

Videhult et al. ${ }^{16}$ analyzed the reliability of IOC of the bile tract in a prospective study of 1117 patients. The authors evaluated the sensitivity, specificity and predictive values of IOC for the diagnosis of choledocolithiasis and established the morbidity associated with the investigation. Routine IOC identified 134 (11\%) cases of common bile duct stones, a rate similar to that observed in the present study (13.58\%). Sensitivity was 97\%, specificity $99 \%$, positive predictive value $95 \%$, negative predictive value $99 \%$, and 
accuracy $99 \%$, showing that IOC is a safe and accurate method for the intraoperative detection of bile duct stones. Anatomic variations were observed in nine $(0.8 \%)$ cases, with no association between iatrogenic injuries and anatomic anomalies. In a German study, Ludwig et al. ${ }^{17}$ showed that only $6 \%$ of institutions still perform routine IOC during laparoscopic cholecystectomy, $49.5 \%$ use selective IOC, and $43 \%$ do not perform any intraoperative diagnostic procedure during laparoscopic cholecystectomy.

Taken together, the literature data and the findings of the present study indicate that the results of routine IOC do not justify the cost of the procedure ${ }^{18}$, increasing the time of surgery and number of false-positive results, overestimating the diagnosis of choledocolithiasis, and mainly increasing the proportion of patients submitted to unnecessary instrumentation of the bile tract and its associated morbidity and mortality risk ${ }^{19-20}$.

\section{Conclusion}

The use of selective cholangiography is safe for the diagnosis of choledocolithiasis. Only $22.37 \%$ of the cholangiography results were positive in cases of suspected choledocolithiasis.

\section{References}

1. Mirizzi P. Operative cholangiography. Surg Gynecol Obstet. 1937;65:702-10.

2. Araújo Neto NP, Gonçalves JE, Bromberg SH, Guz B, Zanoto A. Predição da coledocolitíase pela associação de indicadores clínicos e laboratoriais em dois momentos do pré-operatório da colecistectomia. Rev Col Bras Cir. 2005;32(1):41-6.

3. Metcalfe MS, Ong T, Bruening MH, Iswariah H, Wemyss-Holden SA, Maddern GJ. Is laparoscopic intraoperative cholangiogram a matter of routine? Am J Surg. 2004;187:475-81.

4. Massarweh NN, Flum DR. Role of intraoperative cholangiography in avoiding bile duct injury. J Am Coll Surg. 2007;204(4):656-64.

5. Nickkholgh A, Soltaniyekta S, Kalbasi H. Routine versus selective intraoperative cholangiography during laparoscopic cholecystectomy. Surg Endosc. 2006;20(6):868-74.

6. BerciG,SackierJM,Paz-PartlowM.Routineorselectedintraoperative cholangiography during laparoscopic cholecystectomy? Am J Surg. 1991;161(3):355-60.

7. Borjeson J, Liu SK, Jones S, Matolo NM. Selective intraoperative cholangiography during laparoscopic cholecystectomy: how selective? Am Surg. 2000;66(7):616-8.

8. Crema E, Camara CACR, Pastore R, Teles CJO, Terra Júnior JA, Silva AA. Assessment of positive perioperative cholangiography in patients undergoing elective laparoscopic cholecystectomy. Rev Col Bras Cir. 2010;37(6):403-6.

9. Wu SC, Chen FC, Lo CJ. Selective intraoperative cholangiography and single-stage management of common bile duct stone in laparoscopic cholecystectomy. World J Surg. 2005;29:1402-8.

10. Verbesey JE, Birkett DH. Common bile duct exploration for choledocholithiasis. Surg Clin North Am. 2008;8(6):1315-8.
11. Keus F, Broeders IA, van Laarhoven CJ. Surgical aspects of symptomatic cholecystolithiasis and acute cholecystitis. Best Pract Res Clin Gastroenterol. 2006;20(6):1031-51.

12. Byrne MF, McLoughlin MT, Mitchell RM, Gerke H, Kim K, Pappas TN, Branch MS, Jowell PS, Baillie J. For patients with predicted low risk for choledocholithiasis undergoing laparoscopic cholecystectomy, selective intraoperative cholangiography and postoperative endoscopic retrograde cholangiopancreatography is an effective strategy to limit unnecessary procedures. Surg Endosc. 2009;23(9):1933-7.

13. Fletcher DR, Hobbs MS, Tan P, Valinsky LJ, Hockey RL, Pikora TJ, Knuiman MW, Sheiner HJ, Edis A. Complications of cholecystectomy: risks of the laparoscopic approach and protective effects of operative cholangiography: a population-based study. Ann Surg. 1999;229(4):449-57.

14. Gil SM, Braga JF, Centurion SAR, Gil BZ. Estudo da incidência de coledocolitíase em pacientes com colecistite calculosa aguda e crônica submetidos à colecistectomia vídeolaparoscópica. Rev Col Bras Cir. 2007;34(4):214-7.

15. Topal B, Fieuws S, Tomczyk K, Aerts R, Van Steenbergen W, Verslype C, Penninckx F. Clinical models are inaccurate in predicting bile duct stones in situ for patients with gallbladder. Surg Endosc. 2009;23(1):38-44.

16. Videhult P, Sandblom G, Rasmussen IC. How reliable is intraoperative cholangiography as a method for detecting common bile duct stones? A prospective population-based study on 1171 patients. Surg Endosc. 2009;23(2):304-12.

17. Ludwig K, Bernhardt J, Lorenz D. Value and consequences of routine intraoperative cholangiography during cholecystectomy. Surg Laparosc Endosc Percutan Tech. 2002;12(3):154-9.

18. Livingston EH, Miller JA, Coan B, Rege RV. Costs and utilization of intraoperative cholangiography. J Gastrointest Surg. 2007;11(9):1162-7.

19. Kharbutli B, Velanovich V. Management of preoperatively suspected choledocholithiasis: a decision analysis. J Gastrointest Surg. 2008;12(11):1973-80.

20. Massarweh NN, Devlin A, Elrod JA, Symons RG, Flum DR. Surgeon knowledge, behavior, and opinions regarding intraoperative cholangiography. J Am Coll Surg. 2008;207(6):821-30.

\section{Correspondence:}

Alex Augusto Silva

Rua Floriano Peixoto, 515

38025-070 Uberaba - MG Brasil

Tel.: (55 34)3318-5228

alexuftm@mednet.com.br

Received: June 12, 2013

Review: Aug 14, 2013

Accepted: Sept 12, 2013

Conflict of interest: none

Financial sources: Minas Gerais Research Foundation (FAPEMIG), National Council of Technological and Scientific Development (CNPQ) e Uberaba Teaching and Research Foundation (FUNEPU)

${ }^{1}$ Research performed at Department of Digestive Surgery, Federal University of Triangulo Mineiro (UFTM), Uberaba-MG, Brazil. 